\title{
Virtual Reality to Promote Real del Monte, Mexico
}

\author{
YAIR OLVERA $^{1}$, MARIO GEA $^{2}$, AMÍLCAR VARGAS $^{3}$ \\ Department of Animation and Visual Effects \\ Polytechnic University Metropolitan of Hidalgo \\ Boulevard Acceso a Tolcayuca 1009, Tolcayuca, Hidalgo C.P. 43860 \\ MEXICO
}

\begin{abstract}
The development of a virtual reality app based on the old English Pantheon, located in the Magic Town of Real del Monte, Mexico, is addressed in this text. The purpose of the project is that people can take a virtual tour through the pantheon with a smartphone to know the charm and mystery of its tombs, as well as digitally preserve the place in spite of its continuous deterioration over time. All the stages of the creation of the virtual scenery are described in detail, such as: storyboard, 3D modeling, UV mapping, texturing, lighting, and rendering; as well as the stages to realize the application in virtual reality, such as: camera adaptation, plugins' installation, creation of scripts, relation of camera to the character, and creation of the Android APK. This app offers new ways of advertising historical places of the region and, at the same time, promoting tourism.
\end{abstract}

Key-Words: - 3D modeling, English Pantheon, Mobile app, Tourism Marketing, Virtual reality, Virtual worlds.

Received: May 25, 2020. Revised: October 12, 2020. Accepted: October 31, 2020. Published: November 11, 2020.

\section{Introduction}

The use of Information and Communication Technologies (ICT) has had a strong impact on today's society, covering all areas of daily life, and even changing the mechanisms of access, development and dissemination of information. Tourism hasn't fell behind in that aspect, and little by little, technological programs have appeared to encourage entertainment and exploration of places through various means of communication. They are based on a system of relations between the subject (tourist) and the tourist object (location, company or tourist organization). The subject is the one who receives the services produced by the tourist object [1]. This has a great importance since the promotion of tourism in the market has a concrete value in terms of the economic development of the locality, as well as being an identification of the same.

Technological advances have led to new ways of doing tourism. These new forms produce sensations in people equal or similar to reality, that is, they generate unique experiences regardless of whether these come from reality or imagination, from which the post-tourism concept arises which is also called virtual tourism. Its main characteristic is to generate in people tourist experiences without the need of physical displacement to the places visited [2]. This term tries to generate new ways of tourism by applying technologies such as Virtual Reality (VR) which, through interactive three-dimensional computer simulation, allows the user to feel immersed into an artificial environment, generated from existing or imaginary data. In this way the user can perceive it as real, based on stimuli from sensory organs such as sight and hearing $[3,4]$.

The use of this technology allows the recreation of scenes based on tourist information and data, capable of transcending the barriers of time, space and communication, promoting the tourist possibilities of a place. However, the experiences generated from VR in the context of tourism cannot substitute the real emotions of being physically in a place, independently of the possible inconveniences or dangers that the destination may have [5].

Recent innovation in VR platforms, devices, and content production tools allows for VR to evolve from being a field of technology mainly enjoyed within the gaming communities into the realm of everyday experiences [6]. Since its early conception, VR has been described as a computer-simulated environment with which, and within which people interact $[7,8]$. Using VR devices, people can experience the virtual environment as if he or she were part of it. This is modified in real time as the device senses user's reactions and motions, allowing him or her to perceive a vivid mental representation of the virtual environment, creating the illusion of interacting with and being immersed in it [9].

Virtual experiences help tourists to prepare and motivate to physically visit a destination, besides being a support as an advertising medium to encourage and awaken interest in the user. So 
different public and private organizations bet on the implementation of technological projects that contribute to the mission of attracting tourists [10]. Empirical evidence from various fields of studies demonstrate that VR experiences lead to positive attitudinal and behavioral outcomes, such as consumer learning of products [11], brand recognition, product recall, and memory of experiences [12,13]. Because it is an attractive and motivating element, new applications based on VR must be proposed for experimenting different models, methodologies and experiences.

The objective of this work is not to make an argument in favor of VR, but to enter into its knowledge, since the development of this technology opens up multiple possibilities in the tourist field. For this reason, the purpose is to design and develop a virtual scenario of the English Pantheon, located in the Magic Town of Real del Monte in the State of Hidalgo, Mexico, where users can observe and experiment with the objects that are presented there, as well as creating an app based on VR that serves to encourage tourism not only at the regional level, but also at the national level. This leads to having a 3D digital copy of the place which, despite of constantly receiving maintenance, has been deteriorating over time. Another goal of this study is to investigate the sense of presence during a virtual walkthrough of a tourist destination and how this sense of presence influences a post-VR attitude change toward the destination

\section{ICT and Mexican Tourism}

The use of ICT in the environment related to tourism within the Mexican territory has increased exponentially in recent years. Along with the Internet, they have become indispensable tools to drive tourists to visit different places that are promoted on the web, since they provide them with information regardless of the region where they are and when they require it [14]. Also, through web pages, mobile applications, social networks, digital magazines, electronic commerce, among other means, ICTs have facilitated commercial transactions in the industry by establishing contacts with commercial partners, the distribution of products and the provision of information. [15].

According [16], the arrival of international tourists to Mexico in 2018 was 41.4 million, 2 million 156 thousand tourists higher than that observed in 2017 and equivalent to an annual growth of $5.5 \%$, locating the country in the sixth place worldwide for the arrival of international tourists. The income of foreign currency from international travelers amounted to 22.51 billion dollars, which represented an increase of 5.5\% compared to 2017. It should be noted that the main tourist destinations in the country are: Cancun, Riviera Maya, Los Cabos, Puerto Vallarta and Mexico City, which represent $80 \%$ of the trips of foreign tourists. However, the arrival of national tourists to hotel rooms in 2018 was much higher, reaching 60 million 875 thousand tourists $(73.6 \%$ of the total), while 21 million 850 thousand were international tourists (26.4\% of the total). According to data from the National Institute of Statistics and Geography [17], in 2016 the tourist activity contributed with $8.7 \%$ of the Gross Domestic Product (GDP) of the total of the country. The previous figures have been achieved largely thanks to the fact that with the Internet and new technologies tourists can plan, book and pay for their trip from anywhere in the world, even without the need for intermediaries.

Given the previous facts, it is difficult for an international tourist to visit little-known places, so it should be sought that the national tourist is the one who first visits these places. For this reason, in 2001 the Ministry of Tourism created the Magical Towns Program in collaboration with various governmental entities and state and municipal governments. The program contributes to revaluing a group of towns in the country that have managed to preserve the cultural and historical wealth they contain, and that represent fresh alternatives for visitors [18], in addition to seeking to promote the charms of the country, emphasizing the symbolic attributes, legends, history, important events, daily life, magic, among many other particularities, which emanate in various socio-cultural manifestations. Today, the advertising of the 121 Magical Towns is mainly based on web pages, digital magazines and mobile applications, making it easy to find information about them.

\section{Virtual Reality}

VR has one goal: to convince the user that he/she is somewhere else. It does this by tricking the human brain, specifically, the visual cortex and parts of the brain that perceive motion. A variety of technologies conspire to create this illusion, including: stereoscopic display, motion tracking hardware, input devices, and desktop and mobile platforms [19]. The definition ties VR to technology, in this way it is possible to generate in the viewer the sensation of interaction and immersion, so that he/she feels part of that world [20]. However, VR is more than a computer application. VR requires an intuitive, nonliteral system that represents something that is not there, 
something beyond oneself, something unseen. It requires an immersive interactivity that holds the tension between knowledge and the "unknown", and it requires one first person, that works like one sense derived from hidden sensory forces [21].

This technology allows researchers to define explicitly and exhaustively the sensory cues that carry information about the virtual world. In realworld experiments, it is not possible to control all sensory cues. For example, when studying the contribution of visual cues to navigation, confounding information could be provided by unmeasured smells, sounds, textures and vestibular stimuli (internal information about balance and spatial orientation). VR offers the means to add or remove sensory cues to test the contribution of each one to a neural code, and to build up a 'minimal' set of stimuli needed to produce a given behavior or neural activity pattern [22].

It is known that there are two types of VR: the immersive $\mathrm{VR}$ is one that occurs in a 3D environment with which the user can interact through helmets, gloves and other accessories for the body; the other one is a non-immersive VR in which the user interacts with the virtual world more easily with the use of a keyboard and a mouse. Technically, the immersive VR is an advanced human-machine interface that allows to experiment in a multisensory form, a computer simulation in an interactive way and in real time. It consists of equipment, facilities, software, hardware and applications designed for that purpose.

Immersive VR applications are those that are experienced with several senses, especially vision, audition and touch [23]. Its primary effect is to place a person into a simulated environment that looks and feels to some degree like the real world. A person in this synthetic environment has a specific sense of self-location within it, can move her or his head and eyes to explore it, feels that the space surrounds her or him, and can interact with the objects in it [24]. In VR the effect of entering the world begins with physical, rather than mental, immersion. The state of being mentally immersed is often referred to as having "a sense of presence" within an environment [25]. Presence is defined in literature as the psychological state where a user is feeling lost or immersed in the mediated environment, the degree to which he or she feels physically "present" in a virtual environment, thus, the key concept that explains the effectiveness of VR in various use contexts [26].

VR has typically been portrayed as a medium [27]. As a communication medium, VR shares some characteristics with more traditional media, especially those with which it has a common heritage. It is important for the VR developer (and users) to realize the importance of understanding the deeper aspects of the medium in which they are working. Some virtual worlds are designed with a particular device in mind, and some are designed to be experienced through more than one device. Some virtual worlds are especially suited for and designed to be implemented using a VR interface [25]. In this way, it must be considered from the beginning to what type of audience the product is directed and what the desired message is.

Virtual 3D worlds offer opportunities for tourist marketing companies to target specific markets by offering an innovative environment for potential visitors to explore tourist destinations [28]. As the use of VR increases, its applications within tourism also increases, planning and administration, marketing, entertainment, education, accessibility and preservation of heritage stand out [29]. Despite the above, there is little understanding of how to market these tourist services and the economic impact that they generate in the industry.

\section{English Pantheon of Real del Monte}

Located at the top of one of the mountains of the socalled Magic Town of Real del Monte in the State of Hidalgo, Mexico, it was built in 1851 and donated by the Englishman Thomas Straffon (1824-1862) who, during this time, was working as an official of the mining companies engaged in exploitation of the region. Various celebrities of the entity and even from other countries such as Ireland, Scotland, China, Netherlands, Germany and England have been buried in this pantheon. To this day, it has 758 fine tombstones with the names of those Englishmen that were important for local mining, some with small statues, all surrounded by plants and shaded by trees, as shown in Figure 1 .

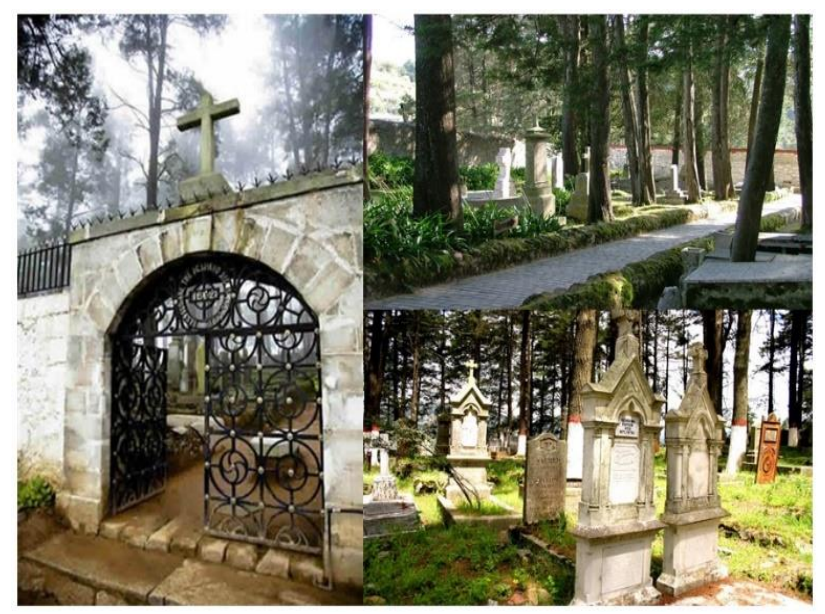

Figure 1. English Pantheon of Real del Monte. 
The gate that protects this pantheon was built in 1869 and it has an interesting legend: "Blessed are the dead who die in the lord". At the entrance to the cemetery there is a Masonic platform, because some of the English who are buried there were Freemasons. The rest of the deceased buried there belonged to the Protestant religion. The symbols of Freemasonry in the form of sarcophagi, fourcornered stars, obelisks and chains represent the union of Freemasons; the well-known five-cornered star in the pantheon means death and light. The tombs are perfectly aligned from west to east, as if they were heading towards Great Britain, where the blood of most of those who lie there came from. One of the most famous tombs in the world is that of the English clown, named Richard Bell, who cheered the country for a long time with Circus Orrín.

Crossing the entrance gate means entering a dense but attractive atmosphere, a disturbing scene, with a certain beauty, though. Walking in this pantheon, so different from the typical Mexican pantheons, make people feel the icy cold that blows in those heights and see the immense trees move with the wind. Listening to the scandalous rumor of nothingness, gives the feeling of being observed while one reads foreign names accompanied by dates of death from the previous century inscribed in the grave.

Both the English Pantheon and Real del Monte are tourist destinations par excellence in the region. However, few advertising strategies have been developed to advertise the place. The strategies are mainly based on triptychs distributed on the roads that surround the community, as well as television reports from regional, and sometimes national, channels. But those strategies are not novel and they are directed mainly to the local public that already has knowledge of the site. Hence the importance of generating multimedia applications that reach more people around the country through the Internet.

\section{Virtual Scenario Development}

The idea is to create a VR app about the English Pantheon to enhance the tourist attraction of this place. To do this, the creation of a virtual scenario using various types of software is proposed. This allows the final product to be experienced in a more real, willing and attractive way, with the sole objective that the user becomes an active subject, and explorer of information [10]. So, in order to have a good organization, it is better to realize a top plane of the English Pantheon, as seen in Figure 2. This allows the app makers to know the exact position of the tombs and the elements around them.

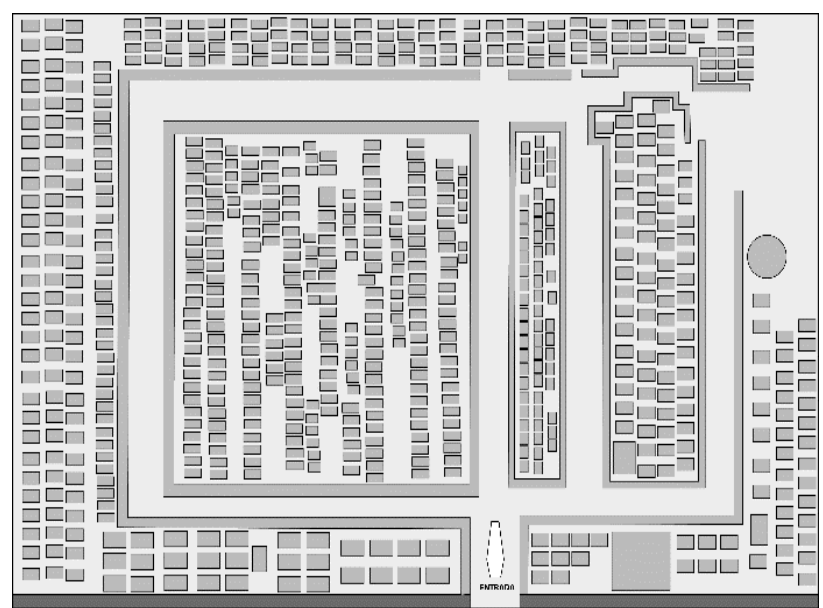

Figure 2. Scheme of the English Pantheon.

After making the sketches and storyboards of what the scenario is like, another important point is to create all 3D models of tombs, trees, fences and other objects that are in the designs of the Pantheon. The basic steps to achieve a 3D object are: modeling, UV mapping, texturing, lighting and rendering, using specialized software like Maya, ZBrush, Photoshop and Blender.

Modeling consists on shaping individual objects, based on a reference image. The UV mapping represents the coordinates of the texture in the model, which in $3 \mathrm{D}$ view coincide with the position of the vertex but have an independent movement in its unfolded form. Texturing is made to increase the detail and realism of the models by incorporating textures, it is an image that is placed on the faces of the polygon. Lighting or shading defines how the faces of a polygon will behave when illuminated by virtual lights. Rendering generates an image from a model, that is, it is the complex calculation developed by a computer designed to generate a $3 \mathrm{D}$ image. Figure 3 shows the comparison between the real tombs and those generated by $3 \mathrm{D}$ modeling.

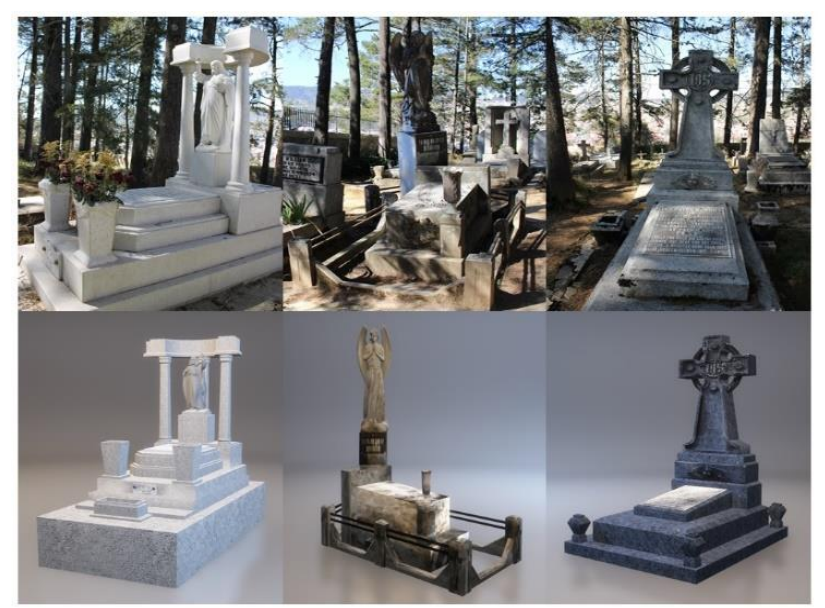

Figure 3. 3D modeling of tombs. 
In general, the digitalization methods used in this text comply with the following steps: presentation of the needs, choice of techniques to be applied, acquisition of field data, data processing, quality control and delivery [30].

Once all 3D models of buildings and objects have been created, they are exported to the virtual environment, which is made in Unity, a software that provides the tools for developing and creating virtual environments. In Unity, all the development of the English Pantheon is done, and the objects are placed in the correct position according to the storyboard. Also, the programming of some objects is carried out so that they have movement capacity, as well as the background music and the sounds are set for certain elements. Finally, the sky is added to the scene, as well as fog and other weather effects. The programming scripts are made in $\mathrm{C \#}$ language. This software allows to see the simulation in motion to check its correct operation. Figure 4 shows the virtual environment created.

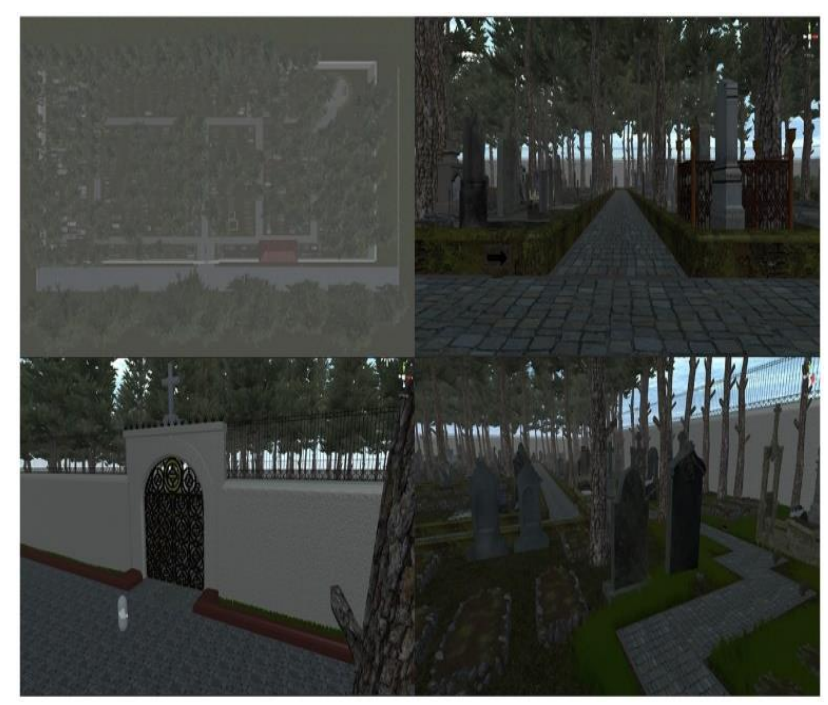

Figure 4. Virtual scenario.

\section{Virtual Reality App}

To develop the application, a methodology that defines in detail all the elements that make up the 3D environment through VR techniques is used. It is based on determining a general panorama of the simulated environment by performing an instructional analysis of its characteristics and needs. Then the modular interpretation of the goals and objectives is elaborated, determining the specifications of the application, which could be considered as the specifications and functions of the virtual world. Finally, the realization of technical specifications is carried out, where physical behaviors, navigation mechanisms and the insertion of multimedia components that complement the virtual environment are assigned. With all this, the virtual world can be stored in a mobile device as a standardized application that has stereoscopic effects and is navigable through the kinematics of the human body through the accelerometer and gyroscope [31].

Once the virtual scenario is done, the application in VR can be used by means of the Google Cardboard platform, which works from mounting a smart mobile phone with an Android or IOS operative system in a folding cardboard base cut out and with two lenses. For the correct use of the platform a flexible architecture based on a graphical interface for mobile devices is needed, which uses a set of application programs and programming languages that are standardized to interact with the Google Cardboard SDK, taking advantage of the capacity of the phones.

The development of this process is summarized in the need in the application for the camera to move by means of a joystick, in which a series of scripts are programmed. This is because the original plugin only contains the script to convert it to VR, but does not provide the movement of the character or camera. For this reason, the Unity main camera is used, adapting the scripts and objects for their movement. The hierarchical structure of the VR camera is as follows: the main object used as "Father" is called VR_GENERAL, this being just an empty object that performs the function of joining the two "Children" objects, called "Cardboard Main" and "Overlay Canvas". The children, in turn, contain objects and scripts, being the most important within the "Cardboard Main" operation, in its structure there are five objects:

1. First Person Controller: Contains scripts that make the movement function for the character and the $360^{\circ}$ movements of the camera, allowing the camera to rotate.

2. Main Camera: Contains a pair of objects called "MC_Left" and "MC_Right", which are the two eyes, dividing the screen with a parallax element, to achieve the effect of VR.

3. Walk Pointer: It is the object that serves as a support to make the camera move using the joystick.

4. Graphics: It is the capsule object that serves to connect everything, pretending to be the character.

5. Stereo render: Contains two elements that provide the project render, giving the final appearance of the project called "Pre-Render" and "Post-Render".

The other "Child" of VR_GENERAL is "Overlay Canvas", which only contains the FPS that acts as 
the screen that allows the user to configure the VR part, this being a Google Cardboard plugin. With the above changes it is possible to make the VR app, as well as move the camera on stage using a joystick.

Before installing the final application, it is necessary to install several plugins and libraries. The first is the JDK, which provides development tools for the creation of programs in Java. It has a compiler that allows to convert source code into bytecode of the Java virtual machine. Then, the installation of the NDK is done, which is a set of tools that allows to implement parts of the application in native code. For certain types of applications, this can help to reuse code libraries written in those languages. The SDK is also installed, which consists of a set of software development tools that allows the creation of applications for a certain computer system. With all this, it is possible to develop the app on Android using Java language. Afterwards, it is transferred to the mobile device where it is successfully executed as shown in Figure 5.

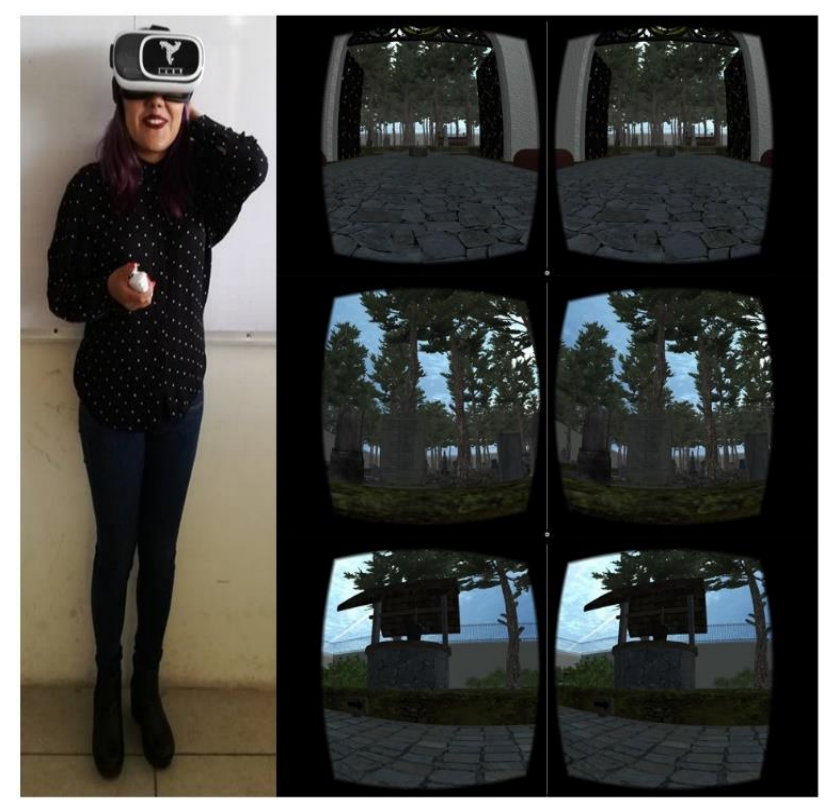

Figure 5. Virtual reality app

Finally, testing is performed to find and solve the problems that exist in the implementation of the application, as well as to verify various aspects, such as: reliability, efficiency, portability, scalability, maintainability, compatibility, usability and capacity. Once the previous steps are done, the beta version of the app is performed, which means that it is practically finished.

The app has a high degree of interaction with the user, who can move in all directions on the stage with the help of the joystick. When standing in front of a grave, information of the person buried there is displayed. Simulated objects appear solid and have an egocentric location much like real objects in the real world, they can be picked up and examined from all sides. The weather is also represented with the typical fog and cold wind of the region, which causes the trees and shrubs to move constantly. Additionally, the sound makes the tour look more real, with the sound of the wind and the birds that live there, as well as the footsteps in the grass and dirt when walking. This to place a person into a simulated environment that looks and feels to some degree like the real world.

As in any project, the measurement and evaluation processes seek to identify the effects and impacts. To measure VR enjoyment, this research refers to the [32] definition of perceived enjoyment, which is the extent to which the activity of using VR technology to experience a tourist destination is enjoyable in its own right. Consequently, to demonstrate the enjoyment and efficiency of the app, it was tested on 50 tourists who arrived at Real del Monte. For this, the complete kit of the app was installed in an information kiosk located at the Magic Town's downtown. It is a place with a great tourist flow, as it provides information on places to visit, restaurants, hotels, tours, etc.

Of the total number of people who used the application, half were from the state of Hidalgo and half were from other states in the country; 29 were men and 21 women; 14 were between 11-30 years old, 26 were between $31-50$ years old, and 10 were over 50 years old; 6 were in high school, 15 were in college, 22 finished college, 2 completed graduate school, and the rest had incomplete studies; 19 had previously visited the site and 31 were for the first time. However, a large part of them did not know the English Pantheon or had not planned to visit it. Among the reasons to visit the place were mines, nature and adventure. Some even mentioned that they knew about the place when Prince Charles of England visited it.

The results were positive, mainly in young people, since they accepted with pleasure and interest the use of new technologies to promote the pantheon; they also managed to handle the joystick and camera movements more quickly, because its characteristics are based on video games. On the other hand, adults had certain difficulties to master the VR, although they recognized that it was an innovative idea. People from the state of Hidalgo loved having a place so known to them in VR, while people from other states were surprised to learn that such a wonderful place was hidden in the mountains of the community. Figure 6 illustrates the use of the app among visitors. 


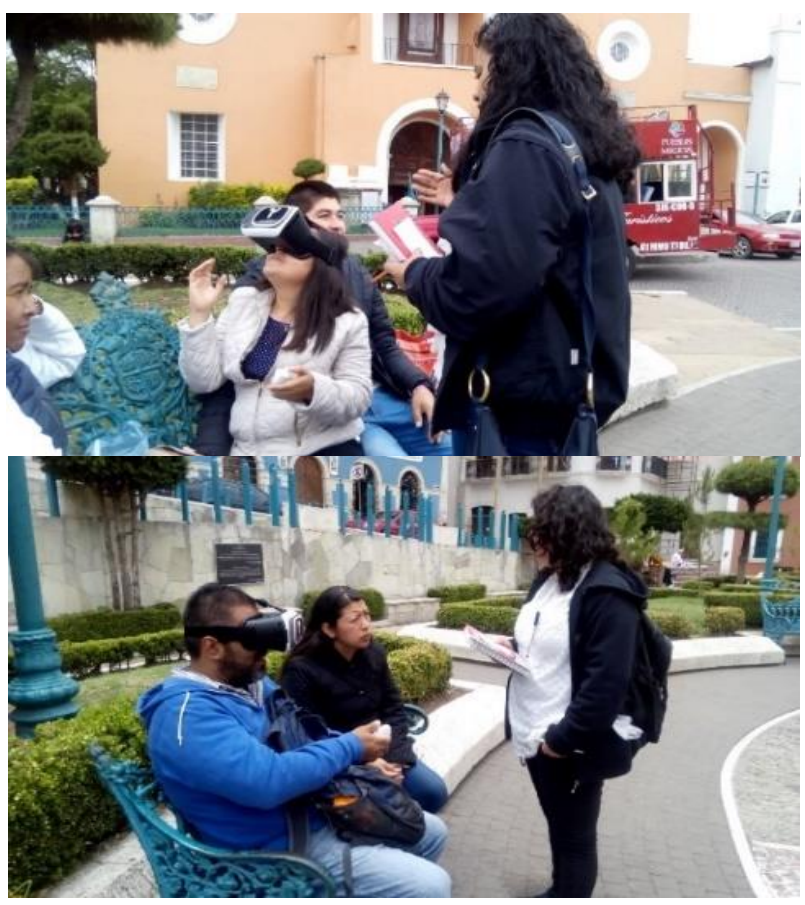

Figure 6. Tests on people of the app.

Also, a brief questionnaire was given to the people who used the app to know their opinion about its development. The results are in Table I. With the information gathered, it is shown that the VR app of the English Pantheon fulfills its purpose of encouraging people to visit it. This can be affirmed because people showed interest in visiting the place by observing how unique the pantheon is and the majesty inside. They considered the importance of using new ways to promote little known tourist places, even more, nowadays that there is more openness and information spreads easily on the media. They also asked for reports to acquire not only the application, but historical information about the English Pantheon and the characters buried there.

Table I quiz about the app.

\begin{tabular}{|l|c|c|}
\hline Question & $\begin{array}{c}\text { Yes } \\
(\%)\end{array}$ & $\begin{array}{c}\text { No } \\
(\%)\end{array}$ \\
\hline $\begin{array}{l}\text { Had you ever experienced a } \\
\text { 3D immersion? }\end{array}$ & 62 & 38 \\
\hline Did you enjoy the virtual tour? & 96 & 4 \\
\hline $\begin{array}{l}\text { Did you like the virtual } \\
\text { environment of the English } \\
\text { Pantheon? }\end{array}$ & 96 & 4 \\
\hline $\begin{array}{l}\text { Do you think the background } \\
\text { music is adequate? }\end{array}$ & 90 & 10 \\
\hline $\begin{array}{l}\text { Do you think that this app } \\
\text { helps to attract tourists to the } \\
\text { town? }\end{array}$ & 86 & 14 \\
\hline
\end{tabular}

The table shows that a large part of the people had used a VR-based application, so they were familiar with the subject. Almost all the people were satisfied using the application and enjoyed the tour for about 5 minutes, considering that it is easy to handle. In general, they thought that the use of technology to advertise small tourist destinations is striking and could help increase the number of visitors. Most of the people would be willing to download the application on their smartphones to have more information about the place, although they would not pay for it.

It is evident that all people have different interests, which depend on many factors such as: where they live, what they studied, how old they are, their life experiences, etc. So, the main utility of the app is to describe and analyze a set of characteristics of the place to show the tourist, through skills such as: perception, attention, understanding, thought, representation of knowledge, memory and language [33]. This is because in today's world many people are consumers of digital technologies, mainly smartphones. The use of these devices allows them to search several touristic places, obtain information, compare places, book tours, among other things; so, this RV app offers an innovative way to reach people, excelling over other advertising media. This encourages tourism and consequently a possible economic and social growth in the region.

The relationship between technology and social development is an important challenge posed by various organizations worldwide. The proposal of social technologies represents a recent movement that seeks to provide technological and material support to the strategies that benefit society in various areas. This consists of a system where a 
technological artifact goes through a process of adaptation to the interests of relevant social groups different from those that gave rise to it [34]. This is the idea of the app, to take an innovative technology and apply it to tourism to promote a community with great cultural and social contributions.

Practically all the existing VR applications promote famous tourist destinations, known museums, popular events, or are just video games. Therefore, generating a high-quality technological product aimed at promoting a small community has great value for society, since it is a development that can hardly be obtained with its own resources. The idea is to create a digital platform where people can view content based on virtual reality and augmented reality to promote places that are little known but have great historical or cultural significance that no other place has. This could help people become more interested in so-called Magical Towns and visit them in the future.

With this app it is shown that the development of VR opens multiple possibilities in the tourism and marketing field. Since the use of these media has been increasing, reaching practically the entire society, especially children and adolescents. Hence the importance of understanding how valuable and important the proposal to introduce virtual models, virtual reality and even augmented reality is in promoting tourism in various locations. Despite the fact that various related apps already exist on the market, the valuable thing about this proposal is that little-known or visited places are promoted, contrary to the other proposals. This new form of user interaction allows for a greater experience with the place. In addition, the fact that the user interacts with their environment and with virtual elements, promote the surprise factor that makes them remember the action and, therefore, the place. This technique applied to marketing not only serves to attract the attention of the consumer, but also provides personalized content, of value and with greater creativity.

Currently, the app is in the hands of the government of Real del Monte. The idea is to first show the app in all the tourist information modules for visitors who arrive to town. Then, they plan to make the app available on the Android and IOS stores, so that anyone can download it.

\section{Conclusion}

The design, development and implementation of a virtual reality application to promote the English Pantheon located in the Magic Town of Real del Monte, Mexico, is described in detail. The purpose is that people can go on a tour of the pantheon through a smartphone to know the beauty of its interior, and thereby encourage tourism in the area. At the same time, it aims to digitally conserve the pantheon in its entirety since it has been deteriorating little by little as time goes by despite the constant maintenance that it receives. The creation process is very slow and complex, because modeling the 3D objects and developing the virtual scenarios require a very detailed work. Also, the files must be light in size so that the application loads fast and does not take up too much space in the installation. When testing the application with people who were in the locality of Real del Monte, the majority agreed that it is an interesting and pleasant way to promote a tourist destination, and they considered going to visit the place. So, the application meets its goal of being a new means of dissemination of tourist information, and it provides empirical evidence to confirm the effectiveness of VR in consumers. Results of this study provide tourist suppliers with validation that VR can be an effective marketing tool.

\section{References:}

[1] N. C. Novás, Promoción y venta de servicios turísticos, Vigo: Ideaspropias Editorial, 2010.

[2] S. Molina, O pós-turismo, São Paulo: Aleph, p. 27, 2003.

[3] G. C. Burdea, and P. Coiffet, Virtual reality technology, NY: John Wiley \& Sons, 2003.

[4] F. Pérez, Presente y futuro de la tecnología de la realidad virtual, Creatividad y Sociedad, Vol. 16, 2011, pp. 15-23.

[5] S. Sussmann, and H. J. Vanhegan, Virtual reality and the tourism product substitution or complement?, ECIS 2000 Proceedings, 2000, p. 117.

[6] I. P. Tussyadiah, D. Wang, T. H. Jung, and M. C. Dieck, Virtual reality, presence, and attitude change: Empirical evidence from tourism, Tourism Management, Vol. 66, 2018, pp. 140-154.

[7] M. J. Schuemie, P. Van Der Straaten, M. Krijn, and C. A. Van Der Mast, Research on presence in virtual reality: A survey, CyberPsychology \& Behavior, Vol. 4, No. 2, 2001, pp.183-201.

[8] J. Diemer, G. W. Alpers, H. M. Peperkorn, Y. Shiban, and A. Mühlberger, The impact of perception and presence on emotional reactions: a review of research in virtual reality, Frontiers in Psychology, Vol. 6, 2015.

[9] W. Wirth, T. Hartmann, S. Böcking, P. Vorderer, C. Klimmt, H. Schramm, and P. Jäncke, A process model of the formation of 
spatial presence experiences, Media Psychology, Vol. 9, No. 3, 2017, pp. 493-525.

[10] L. Haz López, La realidad virtual como herramienta tecnológica para fomentar el turismo en la península de Santa Elena, $3 c$ Tecnología, Vol. 5, No. 3, 2016, pp. 53-67.

[11] K. Suh, and Y. Lee, The effects of virtual reality on consumer learning: an empirical investigation, Mis Quarterly, Vol. 29, No. 4, 2005, pp. 673-697.

[12] T. Kim, and F. Biocca, Telepresence via television: Two dimensions of telepresence may have different connections to memory and persuasion, Journal of computer-mediated communication, Vol. 3, No. 2, JCMC325, 1997.

[13] K. Mania, and A. Chalmers, The effects of levels of immersion on memory and presence in virtual environments: A reality centered approach, CyberPsychology \& Behavior, Vol. 4, No. 2, 2001, pp. 247-264.

[14] C. Berné, M. García-González, M., M. E. García-Uceda, And J. M. Múgica, The effect of ICT on relationship enhancement and performance in tourism channels, Tourism Management, Vol. 48, 2015, pp. 188-198.

[15] D. Shanker, ICT and Tourism: Challenges and Ostrortunities, Proceedings oft he International Conference on Tourism in India-Challenges Ahead, Indian Institute of Management Kozhikode, 2008, pp. 50-58.

[16] Secretaría de Turismo SECTUR (2018). Resultados de la actividad turística 2018. Available: http://www.datatur.sectur.gob.mx/ RAT/RAT-2018-12(ES).pdf

[17] Instituto Nacional de Estadística y Geografía INEGI. (2018). Estadística a propósito del día mundial del turismo (27 de septiembre). Available: http://www.beta.inegi.org.mx/ contenidos/saladeprensa/aproposito/2018/turis mo2018_Nal.pdf

[18] Secretaría de Turismo SECTUR. (2018). Resultados de la actividad turística 2018. Available: http://www.datatur.sectur.gob.mx/ RAT/RAT-2018-12(ES).pdf

[19] T. Parisi, Learning virtual reality: Developing immersive experiences and applications for desktop, web, and mobile, CA: O'Reilly Media Inc, 2015.

[20] L. Heras, and J. Villareal, La realidad virtual en los nuevos paradigmas de la ciencia de datos, Revista Digital Universitaria, Vol. 12, No. 9, 2011.

[21] T. Hohstadt, The age of virtual reality, TX: Lulu.com, 2013.
[22] M. Minderer, C. Harvey, F. Donato, and E. Moser, Virtual reality explored: Neuroscience, Nature, Vol. 533, No. 7603, 2016, pp. 324-325.

[23] M. A. Cruz Morales, A. O. Morales Cárdenas, and A. Ayala Ruiz, Diseño de productos asistidos por realidad virtual inmersiva. Ingeniería mecánica. tecnología y desarrollo, Vol. 2, No. 3, 2006, pp. 93-100.

[24] J. Psotka, Immersive training systems: Virtual reality and education and training, Instructional Science, Vol. 23, No. 5/6, 1995, pp. 405-431.

[25] W. R. Sherman, and A. B. Craig, Understanding virtual reality: Interface, application, and design, NY: Elsevier, 2002.

[26] T. Schubert, F. Friedmann, and H. Regenbrecht, The experience of presence: Factor analytic insights, Presence: Teleoperators and Virtual Environments, Vol. 10, No. 3, 2001, pp. 266-281.

[27] J. Steuer, Defining virtual reality: Dimensions determining telepresence, Journal of communication, Vol. 42, No. 4, 1992, pp. 7393.

[28] Y. C. Huang, K. F. Backman, S. J. Backman, and L. L. Chang, Exploring the implications of virtual reality technology in tourism marketing: An integrated research framework, International Journal of Tourism Research, Vol. 18, No. 2, 2016, pp. 116-128.

[29] D. A. Guttentag, Virtual reality: Applications and implications for tourism, Tourism Management, Vol. 31, No. 5, 2010, pp. 637651.

[30] R. Héno, and L. Chandelier, 3D modeling of buildings: outstanding sites, US: Iste, 2014.

[31] G. Samperio, A. Arcega, M. Sánchez, and A. Navarrete, Metodología para el modelado de sistemas de realidad virtual para el aprendizaje en dispositivos móviles, Pistas Educativas, Vol. 39, No. 127, 2018.

[32] F. Davis, R. Bagozzi, and P. Warshaw, Extrinsic and intrinsic motivation to use computers in the workplace, Journal of applied social psychology, Vol. 22, No. 14, 1992, pp. 1111-1132.

[33] R. Bruning, J. Bueno Alvarez, M. Norby, R. Ronning, J. Sánchez Baides, and G. Schraw, Psicología cognitiva y de la instrucción, Madrid: Pearson Educación, 2005

[34] H. Thomas, and M. Fressoli, En búsqueda de una metodología para investigar tecnologías sociales, Campinas: Editora Kaco, 2009. pp. 113-137. 


\section{Contribution of individual authors to} the creation of a scientific article (ghostwriting policy)

Yair Olvera conducted the investigation on the place and took the references.

Mario Gea developed the virtual environment and programming for the app.

Amílcar Vargas designed the virtual environment and made the 3D models.

\section{Sources of funding for research presented in a scientific article or scientific article itself}

This research was funded by Polytechnic University Metropolitan of Hidalgo in conjunction with the municipality of Real del Monte, Mexico.
Creative Commons Attribution License 4.0 (Attribution 4.0 International, CC BY 4.0)

This article is published under the terms of the Creative Commons Attribution License 4.0

https://creativecommons.org/licenses/by/4.0/deed.en_US 